\title{
The cultural erosion of Indigenous people in health care
}

— Cite as: CMAJ 2017 January 16;189:E78-9. doi: 10.1503/cmaj.160167

dealized versions of health care are common, and access to health care is often viewed as an unambiguous good. In the social determinants of health literature, for example, access to health care is treated as an intermediate determinant of health. This conceals a simplistic inference: the better your access to health care, the better your health. The reality is more complex: a modern industrial health care system can be a determinant of ill health, especially where it is culturally unsafe. At present, Canadian health care for Indigenous people is not culturally safe owing to the ways that health law, health policy and health practice continue to erode Indigenous cultural identities.

The origins lie at the colonial foundations of Canada. Colonialism is the primary distal determinant of Indigenous ill health. ${ }^{1,2}$ As a process of enforced assimilation of Indigenous peoples, the drive to assimilate Indigenous communities into mainstream Canada continues to this day. ${ }^{3}$ Contemporary health care contributes to assimilation through what one Anishnabe healer describes as "cultural erosion" (Tom Chisel, Sioux Lookout First Nations Health Authority: personal communication, 2015). As I use the phrase, it refers to the damage to individual and cultural Indigenous identities, with consequent ill health, that is inflicted by Canada's health care system. It is a problem of racism arising from the imposition of Canadian health law and health policies on Indigenous communities.

Racism affects every aspect of health care delivery for Indigenous peoples in Canada. ${ }^{4}$ To understand cultural erosion, systemic and epistemic racism merits particular attention. Systemic racism concerns the unjust distribution of power that is built into law, policy and economic practice. It is the imposition and perpetuation of inequities through governance, rather than through in- dividual intention, decision or behaviour. Examples are commonly bureaucratic. Dr. Michael Kirlew, a community physician for Wapekeka First Nation, cites two (personal communications, 2015/16). First, federal Non-insured Health Benefits medical referral forms require physicians to provide a patient's personal health information irrespective of consent from the Indigenous patient. If the physician does not provide the information, the referral is denied. Second is the routine denial of requests for medical transportation - for example, Indigenous children from remote communities being denied travel for care despite their physicians' judgment. Another familiar example is the underfunding of the nursing stations of northwestern Ontario and Manitoba. ${ }^{5}$

Canadian health care is founded on systemic racism through the violent unilateral imposition of Canadian social, economic, cultural and political dominance over

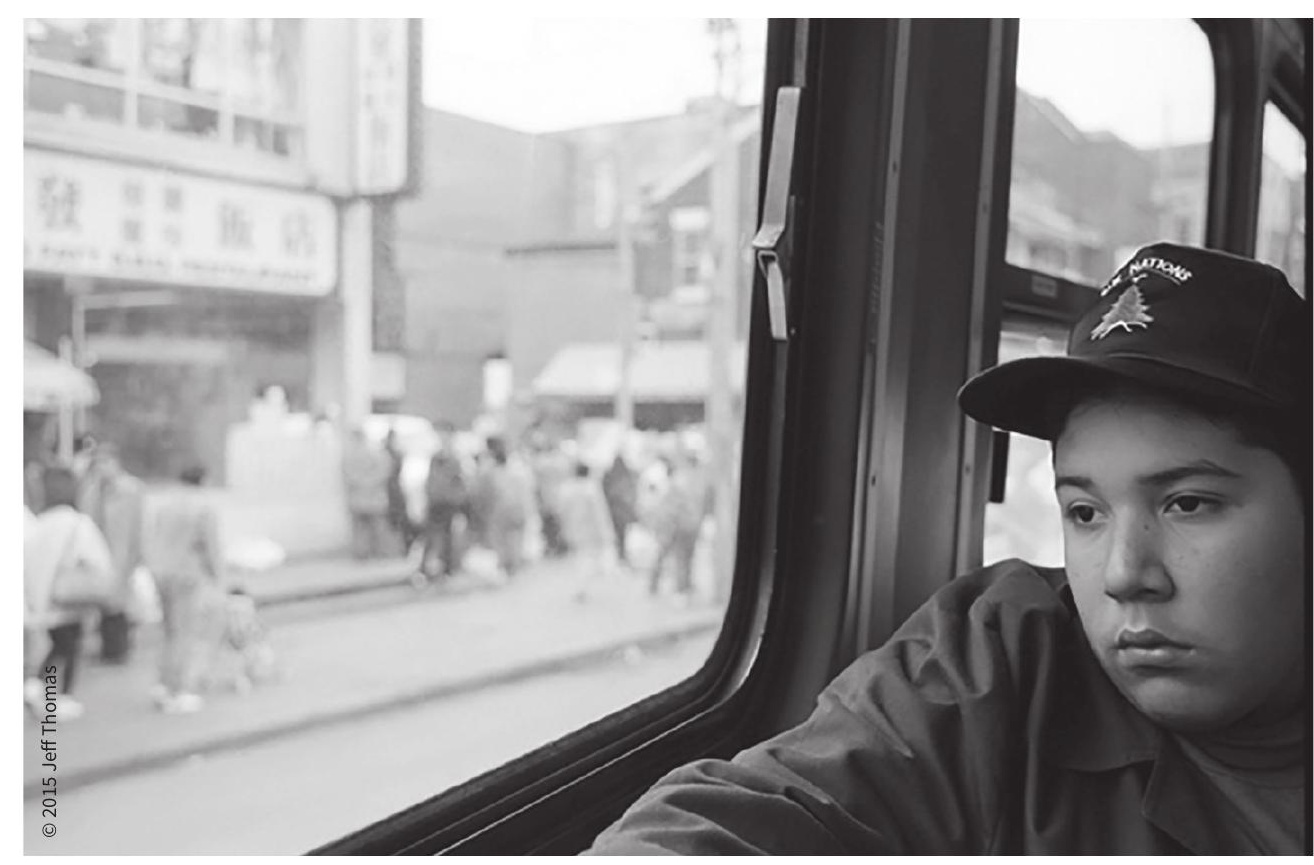

Dream/escape: Dundas Street Car, Toronto, Ont. (www.jeff-thomas.ca; the photographer has obtained consent from the boy in this image.)
Indigenous land and lives under section 91(24) of the Constitution Act, 1867, Indians, and Land Reserved for the Indians, as well as under the Indian Act, 1985. The Truth and Reconciliation Commission (TRC) of Canada ${ }^{6}$ describes it succinctly:

Canada asserted control over Aboriginal land. In some locations, Canada negotiated Treaties with First Nations; in others, the land was simply occupied or seized. The negotiation of Treaties, while seemingly honourable and legal, was often marked by fraud and coercion, and Canada was, and remains, slow to implement their provisions and intent.

Indigenous peoples were tricked out of, robbed of or pushed off their traditional lands, with the consequent erosion of their own complex systems of spirituality, law, trade, governance and health. Health law and policy in Canada is part of this unilateral assertion of governance, and thus, 
despite the technical excellence or best intentions of individual practitioners, is a priori systemically racist.

Epistemic racism - the imposition of one world view over another - also contributes to cultural erosion. One example is the privileging of mainstream biomedical knowledge over Indigenous healing practices and traditions. Anishinabek health laws, customs and practices, for instance, are often not permitted to influence local health institution practices, regardless of their merits. Where they are permitted, they are subordinated to provincial and federal legal and health norms. Epistemic racism explains the diminution and alienation experienced by Indigenous healers
- dialogue with Indigenous peoples to identify and eliminate health care inequities

- acknowledge, respect and address the distinct health needs of Métis, Inuit and off-reserve First Nations people

- provide sustainable funding for existing and new Aboriginal healing centres to address the harms caused by residential schools

- in collaboration with Indigenous healers and elders, recognize as medically legitimate the value of traditional healing practices

- hire and retain Indigenous health care professionals, as well as ensure that all staff have cultural competency training.

\section{The basic moral principles familiar to all health care professionals o blige us to end cultural erosion.}

owing to disrespect for their knowledge and cultural roles. Epistemic racism is also evident in resource allocation - for example, if a health care facility that serves a substantial Indigenous population upgrades technology instead of building a requested sweat lodge.

Systemic and epistemic racism work in tandem. They ensure that only biomedical knowledge is taken seriously; they shape how scarce economic resources are distributed and to whom; they allocate and deny respect and thereby determine who is paid and how much; and they influence medical training, determining what counts as a medicine, medical intervention or treatment. Such inequities affect which patients have access to which health care resources, as well as the quantity and quality of the care. Hence, contemporary Canadian health law, policy and practices continue the cultural erosion of Indigenous healing and cultural traditions begun at the foundation of Canada.

Nonetheless, much can be done. The Truth and Reconciliation Commission calls to action provide systemic suggestions: ${ }^{6}$

- recognize the Indigenous health care rights enshrined in international and national law
Two principles from the cultural safety literature are also invaluable: first, that Indigenous peoples should be empowered to determine what is culturally safe; and, second, that health care professionals need to recognize how their advantages and power may distort health care decision-making. ${ }^{7,8}$ In particular, we must share power and compensate for or eliminate unjust advantages. Health worker expertise becomes considerably more valuable for marginalized communities once cultural safety is priortized. For example, a skilled emergency department doctor is no use if patients don't come to emergency departments because of systemic or interpersonal racism. Referrals for medical interventions are pointless if Health Canada won't allocate appropriate resources. A proper dialogical relationship with Indigenous groups allows Indigenous peoples to coshape a culturally safe health care environment and ensures that health institutions adequately serve Indigenous interests.

Practical options for action are many: engage with Indigenous healers and elders; pay them well and include them in policymaking; provide ongoing antiracism education; build, maintain and adequately staff sweat lodges, where appropriate; advocate for change to harmful policies like those of the Non-insured Health Benefits to make them consistent with superior provincial health care norms; advocate for transformation of health law; and perhaps most important, support Indigenous sovereignty and the treaty relationships - especially as they relate to health care.

The basic moral principles familiar to all health care professionals oblige us to end cultural erosion. Restitution for the extraordinary harms inflicted on Indigenous peoples is required by moral justice; recognition of human and cultural identity is mandated by respect for persons; and beneficence and nonmaleficence, interpreted through the lens of cultural safety, promote the best health outcomes. Ending the ongoing erosion of Indigenous cultures requires integration of these principles, as well as the TRC's calls to action, into personal behaviours, health policy-making and health law.

\section{Richard Matthews PhD}

Centre for Healthcare Ethics, Lakehead University, Thunder Bay, Ont.

\section{References}

1. Czyzewski K. Colonialism as a broader social determinant of health. Int Indig Policy J 2011;2:1-14.

2. Reading C, Wien F. Health inequalities and social determinants of Aboriginal peoples' health. Prince George (BC): National Collaborating Centre for Aboriginal Health; 2009.

3. Palmater P. Genocide, Indian policy, and legislated elimination of Indians in Canada. Aborig Policy Stud 2014;3:27-54.

4. Allan B, Smylie J. First Peoples, second class treatment: the role of racism in the health and wellbeing of indigenous peoples in Canada. Toronto: Wellesley Institute: 2015.

5. Access to health services for remote First Nations communities. Ottawa: Office of the Auditor General of Canada; 2015.

6. Honoring the truth, reconciling for the future: summary of the final report of the Truth and Reconciliation Commission. Winnipeg: Truth and Reconciliation Commission of Canada; 2015.

7. Brascoupé S, Waters C. Cultural safety: exploring the applicability of the concept of cultural safety to Aboriginal health and community wellness. J Santé Autochtone 2009;5:6-41.

8. Gerlach A. A critical reflection on the concept of cultural safety. Can J Occup Ther 2012;79:151-8.

This article has been peer reviewed.

Acknowledgements: The author thanks the following for their support: Elder Tom Chisel, Sioux Lookout First Nations Health Authority; Professor Dennis McPherson, Lakehead University; and Dr. Michael Kirlew, physician for Wapakeka First Nation. He also acknowledges the editorial support of Ms. Emma Woodley. 